\title{
Review of antihemophilic factor injection for the routine prophylaxis of bleeding episodes and risk of joint damage in severe hemophilia $A$
}

This article was published in the following Dove Press journal:

Vascular Health and Risk Management

28 January 2010

Number of times this article has been viewed

\author{
Hans-Christoph Rossbach \\ Division of Pediatric Hematology/ \\ Oncology, St. Joseph Children's \\ Hospital, Tampa, FL, USA
}

\begin{abstract}
Individuals with severe factor VIII deficiency experience recurrent hemorrhages and develop progressive joint damage. Large retrospective, nonrandomized studies of patient cohorts followed over decades show that factor prophylaxis initiated at an early age before the onset of recurrent bleeding reduces the incidence of hemophilic arthropathy. Two recent prospective, multicenter, randomized trials conducted in Europe (the ESPRIT study) and the USA (the Joint Outcome Study) confirm the efficacy of prophylaxis in the prevention of hemarthroses and arthropathy. Regular prophylaxis initiated in early childhood enhances the quality of life for patients with severe hemophilia and reduces the risk of inhibitor development. The substantial costs of such preventative therapy may be offset by the reduced expenditures that the care of degenerative joint disease in adult hemophilia patients would otherwise require.
\end{abstract}

Keywords: hemophilia, factor VIII, prophylaxis, arthropathy, bleeding

\section{Introduction}

Deficiency of factor VIII (FVIII) causes hemophilia A, the most common severe bleeding disorder in humans. FVIII plays a pivotal role in physiologic coagulation. It serves as a cofactor for factor IX, amplifying its catalytic activity by several orders of magnitude.

Hemophilia has been recognized since antiquity as a distinct clinical entity. Egyptian papyri and Hebrew Talmudic documents contain descriptions of this disorder. The first accurate account in the modern medical literature dates back to the early 19th century. The delineation of its genetic transmission and its characterization as hemophilia followed soon thereafter. ${ }^{1}$ The discovery in 1937 that administration of normal plasma corrects the prolonged clotting time of hemophilic blood inaugurated the modern era of treatment and prophylaxis. ${ }^{2}$

Hemophilia, an x-chromosome linked disorder, occurs in 1 per 5,000 male births. Eighty-five percent of affected individuals have hemophilia A, which is caused by a wide range of FVIII gene mutations. ${ }^{3}$ Half of all patients have severe disease, defined as a factor level of $0.01 \mathrm{IU} / \mathrm{mL}(1 \%)$ or less. Bleeding episodes often occur with minimal or unknown trauma. Ninety percent of patients suffer from recurrent hemorrhage into their joints or muscles, typically beginning in the toddler age. Once hemophilic arthropathy ensues, progressive joint damage leads to debilitating dysfunction and chronic pain.

Before the availability of clotting factor concentrates, the life expectancy of patients with severe hemophilia was markedly decreased. ${ }^{4-6}$ In contrast, patients 
with moderate hemophilia, characterized by FVIII levels from 0.01 to $0.05 \mathrm{IU} / \mathrm{mL}$ ( $1 \%$ to $5 \%$ ), by and large bleed only after trauma and experience near normal quality and length of life.

The advent of plasma-derived and recombinant technology-produced FVIII concentrates has revolutionized the care of individuals with severe hemophilia. This review focuses on the use of FVIII for the treatment and prophylaxis of hemarthroses, the clinical hallmark of this disease. Prophylaxis, a prerogative of developed countries because of the high cost of factor concentrates, has shifted the main objective of hemophilia treatment from avoidance of bleeding short-term to the prevention of secondary complications and preservation of long-term quality of life.

\section{Principles of treatment and prophylaxis}

Hemophilia therapy aims to treat and prevent acute bleeding episodes, to minimize related complications, and to maintain normal joint physiology.

On-demand factor infusion, also known as episodic therapy, is defined as therapy to abrogate an acute hemorrhage. Cessation of bleeding does not reverse the deleterious effects on synovial tissues by the blood already accumulated in the affected joint.

In patients without neutralizing inhibitor, each FVIII unit per $\mathrm{kg}$ body weight infused raises the plasma factor level by $2 \%$ points. FVIII levels sufficient for cessation of bleeding vary depending on the site and severity of the hemorrhage. Appropriate levels range from 30\% to 50\% for intra-articular, muscular, and mucosal bleeds to $100 \%$ for central nervous system hemorrhage. For the purposes of prophylaxis, FVIII trough levels of only $1 \%$ to $5 \%$ prove adequate.

Preventative factor infusion implies replacement therapy in advance of anticipated activity likely to result in bleeding in the otherwise unprotected individual. Prophylactic factor infusions aim to prevent bleeding episodes on an ongoing basis.

Secondary prophylaxis connotes therapy instituted after hemarthroses have already occurred, while primary prophylaxis is initiated before such bleeds ensue. According to the European Paediatric Network for Haemophilia Management (PEDNET), two definitions of primary prophylaxis are now in use. Primary prophylaxis A demands factor infusions after the first joint bleed but before the age of two years. Factor therapy initiated before the age of 2 years with no prior hemarthroses defines primary prophylaxis B. ${ }^{7}$ Prevention of joint degeneration rather than prevention of bleeding episodes constitutes the main goal of prophylaxis.

\section{Factor VIII products}

Following the 1964 landmark observation that slowly thawed frozen plasma contains a precipitate rich in FVIII, henceforth known as cryoprecipitate, ${ }^{8}$ plasma-derived (p/d) FVIII concentrates became available in the 1970s and 1980s. ${ }^{9}$ These concentrates are now subjected to virus reduction and inactivation methods. The integration of ion-exchange and immuno-affinity chromatography into the manufacturing process further enhances the purity of FVIII and increases its specificity.

The rapid development and commercialization of recombinant clotting factors was facilitated by the catastrophic impact of viral contamination of $\mathrm{p} / \mathrm{d}$ factor concentrates in the 1980's. Characterization of the human factor VIII gene, ${ }^{10}$ the molecular cloning of its cDNA, ${ }^{11}$ and the transfection of mammalian cells allowed the large-scale production of full-length recombinant FVIII preparations (rFVIII) and their use for human therapy. ${ }^{12,13}$ rFVIII products omit the requirement for human blood or plasma and offer freedom from viral transmission.

Despite the use of bovine or human albumin used as stabilizers in first and second generation rFVIII products, no viral transmission has been reported in decades of use. Second-generation recombinant factors, available since 1999, contain nonprotein stabilizers but continue to use albumin in the initial cell culture. Third-generation products are manufactured without foreign animal or human protein from synthesis to final formulation. ${ }^{14}$ Recombinant factors derived from genetically engineered hamster ovary or kidney cells are purified with mouse monoclonal antibodies and therefore pose the theoretical risks of animal pathogens.

Recombinant and p/d FVIII concentrates of different degrees of purity have shown similar behavior in vitro and equivalent clinical efficacy in bleeding control and prophylaxis. Head-to-head comparison studies of first- vs second-generation rFVIII products ${ }^{15}$ as well as second- vs third-generation products showed comparable results. ${ }^{16}$

Clinical trials with previously treated and untreated patients have documented safety and efficacy of rFVIII. The first large-scale trial of rFVIII for acute bleeding reported 101 previously transfused patients, 64 of whom had severe hemophilia. After a median follow-up of almost five years since first exposure to rFVIII, treatment response was deemed excellent. ${ }^{17}$ In an updated report totaling 1,362 bleeding 
episodes, 65\% resolved past 1 infusion, and $92 \%$ past 1 to 3 infusions. ${ }^{18}$ Equivalent hemostatic responses of more than $90 \%$ to 1 or 2 factor infusions were seen in subsequent trials with $79^{19}$ and $71^{15}$ previously untransfused as well as pretreated patients. ${ }^{20} \mathrm{~A}$ B-domain-deleted rFVIII product showed a pharmacokinetic profile equivalent to that of a fulllength monoclonal antibody-purified pd-FVIII, and similar hemostatic efficacy and safety. ${ }^{21}$

It has been emphasized that dosage requirements vary considerably among individual patients and that therapy requires adjustments based on clinical outcome (bleeding frequency and joint status) as some patients with factor levels less than $1 \%$ do not bleed while others do despite trough levels of $>3 \% .^{22}$

\section{Prophylaxis in nonrandomized studies}

Acute hemarthrosis is the clinical hallmark of hemophilia. Vessels of the synovial membrane bleed into the articular space spontaneously or with minimal trauma. Iron deposition precipitates an inflammatory reaction, the release of oxidative products, and vascular proliferation. ${ }^{23-25}$ Synovial hyperemia and hypertrophy lead to destruction of cartilage and bone. Degenerative arthritis, quantified by the Pettersson score ${ }^{26}$ results in functional impairment and chronic pain. Joint disease reduces physical fitness and muscular strength, creates muscle atrophy, and in a vicious cycle exacerbates articular instability and repeated bleeding episodes. Children with hemophilia may have reduced bone mineral density compared to age- and gender-matched controls. ${ }^{27}$ Hemarthroses begin in the toddler age. Ankle, knee, and elbow joints are most commonly affected. The tendency to bleed correlates inversely with the endogenous FVIII level. Individual patterns of bleeding, however, vary substantially even in patients with FVIII levels of less than 1\%, although most patients experience 15 or more spontaneous hemorrhages per year.

Long-term follow-up has shown progressive joint degeneration in more than half of patients within 6 years from the first bleeding episode, often necessitating restriction of activity. A linear relationship between the severity of arthropathy and the cumulative number of intra-articular hemorrhages has been demonstrated. ${ }^{28-30}$

Recognition of the superior clinical outcome of patients with moderate hemophilia and factor levels even as low as $1 \%$ or $2 \%$ suggested that a sustained therapeutic increase in factor levels in patients with severe disease and induction of a moderate clinical phenotype might improve hemostasis, favorably affect the frequency of hemarthroses, and prevent or at least delay the onset of degenerative arthritis.

Experience with cryoprecipitate infusions in Holland and Sweden suggested that hemarthroses can indeed be curtailed. ${ }^{31,32}$ Prophylactic p/d FVIII infusions effected a substantial reduction in the frequency of bleeding episodes. Lower dose infusions given daily were comparable to higher doses infused 3 times per week. ${ }^{33}$ Subsequent experience has proven that factor therapy initiated after the first several joint bleeds, now defined as secondary prophylaxis, can reduce further bleeding. Deterioration of joint anatomy and function, however, is irreversible. ${ }^{34}$ Despite stringent prophylactic therapy initiated as early as after 3 to 6 joint bleeds when baseline clinical and radiologic scores were still normal, follow-up at 3 years detected the development of arthropathy. ${ }^{35}$

Large retrospective cohorts followed over decades in several European countries have shown prophylaxis initiated at an early age before the onset of recurrent bleeding to reduce hemophilic arthropathy. Swedish patients monitored longitudinally provided evidence that early prophylaxis aimed to produce FVIII trough levels above $0.01 \mathrm{U} / \mathrm{mL}$ translates into improved outcome. While such secondary prophylaxis did reduce the bleeding frequency, already established arthropathy did not only persist but worsened. In contrast, factor therapy initiated at the age of 1 to 2 years and given on a 2 to 3 times a week basis prevented arthropathy in adulthood. ${ }^{36,37}$ The timing of initiation of prophylaxis independently predicted the development of arthropathy, whereas dose and infusion intervals did not. Treatment before the age of 3 years prevented arthropathy in most patients. ${ }^{38}$ Long-term follow-up of retrospective cohorts of Dutch $^{29}$ and German ${ }^{35}$ patients corroborated the Swedish experience. No arthropathy developed in patients with one or no bleed prior to initiation of prophylaxis at the age of 1 to 2 years. The later in life prophylaxis started, the more prevalent the arthropathy became. These data have led to the current definition of primary prophylaxis, ie, prophylaxis initiated before the age of 2 years and after no more than one joint bleed. ${ }^{7}$

Daily factor infusions have been calculated to be most effective, resulting in a substantial decrease in overall factor use. ${ }^{39}$ Such intensive therapy, however, imposes a heavy burden on patients and their families and cannot easily be sustained over years of treatment.

The original Swedish, high-dose, prophylactic factor regimen prescribed 25 to $40 \mathrm{IU} / \mathrm{kg} 3$ times a week, targeting a preinfusion factor level exceeding $1 \%$. In contrast, physicians 
in Holland employed an intermediate-dose regimen with adjustments according to bleeding pattern irrespective of factor trough levels. Follow-up over 2 decades of boys born in these two countries from 1970 to 1990 revealed a reduction in hemarthroses at the expense of 2-fold higher factor consumption in the Swedish compared to the Dutch cohorts. ${ }^{40}$

The Canadian Hemophilia Dose-escalation Prophylaxis trial also investigated an individualized, intermediate-dose therapeutic approach as an alternative to full-dose prophylaxis. In this 5-year study, 25 boys between the ages of 1 and 2.5 years without inhibitors received prophylaxis. Initial therapy started at $50 \mathrm{IU} / \mathrm{kg}$ weekly (step 1) and escalated to $30 \mathrm{IU} / \mathrm{kg}$ twice weekly (step 2) if a target joint developed (defined as three bleeds into a single joint) or if bleeding frequency was deemed intolerable (four joint and/or significant soft tissue bleeds) over a 3-month period. Persistence of bleeding prompted escalation to full prophylaxis (step 3 ). After a median follow-up of 46.4 months, 36\% of patients escalated to step 2, and $16 \%$ progressed to step 3. Joint outcome data as defined by the Pettersson score were observed to be good over the study period. ${ }^{41}$ An updated report on this tailored prophylaxis was recently published..$^{42}$ After a median follow-up of 4.1 years, the median time to escalate to twiceweekly therapy was 3.4 years. Nine of the 25 boys developed target joints. On average, patients experienced 1.2 joints bleeds per person-year and consumed $3656 \mathrm{IU} / \mathrm{kg} /$ year. At the end of the study period, clinical and radiographic joint examination scores were normal. The investigators concluded that most boys will have little bleeding and maintain good joint function on tailored prophylaxis with reduced FVIII consumption.

Based on these early experiences and apparent benefits of prophylaxis, the World Health Organization, ${ }^{43}$ the National Hemophilia Foundation, ${ }^{44}$ and the World Federation of Hemophilia ${ }^{45}$ all recommend preventative therapy in children.

Results of a multicenter nonconcurrent cohort study were published more recently. ${ }^{46}$ Forty-two children received primary prophylaxis following their first bleeding episode. Patients in this group were frequency-matched (year of birth, catchment area) with 67 patients receiving on-demand therapy with an early switch to secondary prophylaxis. In a multivariate analysis adjusted for hemophilia mutation type and presence or absence of thrombophilia, the Pettersson score was investigated at a median age of 12.5 years in joints with at least one documented bleeding episode. No statistically significant differences were identified between the two groups. The study investigators were unable to conclude a superior outcome of primary prophylaxis over on-demand therapy with an early switch to secondary prophylaxis. The interpretation of these results has been disputed as the investigators considered a bleeding history of only 6 months before the initiation of the study rather than a life-time, cumulative history of hemarthroses. Because of this misleading definition of primary versus secondary prophylaxis, the protective effects of primary prophylaxis may have been underestimated. ${ }^{47}$

\section{Practice patterns}

Throughout the developed countries, practice patterns of FVIII therapy differ widely. Factors influencing therapy include the cost of factor concentrates, the perception of the advantages of such therapy, lifestyle and bleeding patterns, the fear of complications from intravenous devices often required in young children with poor intravenous access, inhibitor development, and until recently, the lack of randomized clinical trials.

In the Netherlands and Sweden, primary prophylaxis is now almost universal. In Dutch patients under 16 years, prophylaxis increased from $34 \%$ in 1972 to $86 \%$ in 2001, while hospital admissions decreased from $47 \%$ to $18 \%{ }^{48}$ A global survey of treatment practice patterns of more than 10,000 pediatric and adult patients disclosed virtually all Swedish children receiving prophylaxis. ${ }^{49}$

The results of the 2006 Canadian national haemophilia prophylaxis survey revealed a similar trend..$^{50}$ Among 2161 patients, $69 \%$ received prophylaxis, defined as at least once weekly factor infusion for more than 45 weeks per year, including $84 \%$ of children and $55 \%$ of adults over 18 years. In comparison to the Canadian 2002 survey, the use of prophylaxis in children less than 6 year increased from $49 \%$ in 2002 to $73 \% 4$ years later. In general, more people including adults were on prophylaxis, and prophylaxis started earlier as well.

In contrast, replacement therapy for hemophilia in Japan is far less common. ${ }^{51}$ Only $24 \%$ of boys under the age of 2 among 1267 patients queried received primary prophylaxis, but half the patients aged 2 to 14 received secondary prophylaxis. Surveys of treatment centers in the United States disclosed similarly low numbers. ${ }^{52} 4129$ patients in 52 centers showed $25 \%$ of children younger than 5 years and $13 \%$ of all patients on primary prophylaxis. A more recent investigation revealed the prevalence of primary prophylaxis only slightly higher at $17 \% .{ }^{53}$ Blanchette et al found discordant data in a query of North American hemophilia centers. ${ }^{54}$ Seventy-seven percent of pediatric patients in Canada were 
on primary prophylaxis versus $47 \%$ in the USA. Reasons for these divergent findings are unclear.

\section{Prophylaxis in adulthood}

Adherence to a prophylactic regimen and the rate of self infusion drop precipitously among young adults. ${ }^{53}$ Few published studies address this issue. An investigation in Denmark and the Netherlands with 80 patients and a median follow-up of 19 years revealed that $35 \%$ discontinued prophylaxis at a median age of 21.5 years. ${ }^{55}$ These patients subsequently experienced only 3 joint bleeds per year. The median clinical and Pettersson scores of the cohorts on and off prophylaxis were identical at follow-up 4 years later.

A larger European survey of practice and outcome data identified a lack of consensus on discontinuation or modification of prophylaxis in adolescent and adult patients. ${ }^{56}$ No consensus existed on the indication of reintroduction of prophylaxis at a later stage of life. Approximately half of a cohort of 218 patients successfully reduced or stopped prophylaxis upon reaching adulthood. Twenty-six of 92 (28\%) patients who stopped prophylaxis required reintroduction of therapy. Twelve of $59(20 \%)$ of those who reduced the intensity of prophylaxis had to reintroduce a more rigorous regimen. The survey revealed the preferred age of modification to be 16 to 20 years. No consensus existed on the particular prophylactic regimen recommended.

Data from these studies indicate clinical features suggestive of a milder bleeding phenotype in those patients who were able to permanently switch to on-demand therapy, including later age at start of prophylaxis, a lower-dose factor regimen, and decreased incidence of breakthrough bleeds. These characteristics may be useful in identifying patients able to discontinue prophylaxis in early adulthood.

A majority of respondents would consider (re-) starting prophylaxis at age 50 years.

Tagliaferri et al assessed the effects of secondary prophylaxis started in adolescent and adult hemophiliacs. A 90\% reduction in the mean annual number of joint bleeds in patients on prophylaxis accompanied an equal decrease in days lost from work or school. ${ }^{57}$ Compared to the patients on episodic factor therapy, individuals on prophylaxis had an increased consumption of factor concentrates with corresponding higher costs balanced by marked clinical benefits with improved quality of life.

It has been argued that the challenge in the care of young adults lies not in the discontinuation of prophylaxis but in optimizing the efficiency by individualizing prophylaxis doses and frequency according to life style and bleeding pattern. ${ }^{58}$ Lack of clinical trials and consensus led the Adult Prophylaxis Study Group to identify a compelling need for evidence-based guidelines. ${ }^{59}$

\section{Randomized trials of hemophilia prophylaxis}

Until two years ago, lack of data derived from well-designed prospective FVIII trials was cited as insufficient evidence for primary factor prophylaxis. Support for such prophylaxis in patients with severe hemophilia A came predominantly from the retrospective, comparative cohort studies outlined above. Four small randomized studies enrolled a total of only 44 patients and were thus too limited to allow for definitive conclusions. One of these studies evaluated patients with hemophilia B and two were conducted over 30 years ago. The study designs precluded a meaningful meta-analysis due to divergent intervention and patient age. ${ }^{60-63}$

The results of two more recent, large, prospective, multicenter, randomized clinical trials have been published in the last two years. In Europe, the ESPRIT study confirmed the feasibility and efficacy of prophylaxis in the prevention of hemarthroses and arthropathy. ${ }^{64}$ Forty children with severe hemophilia A (FVIII < 1\%) and a median age of 2 years were randomized to receive prophylaxis with $25 \mathrm{IU} / \mathrm{kg} 3$ times a week with dose adjustments to maintain trough levels above $1 \%$, or on-demand therapy with a minimum of $25 \mathrm{IU} / \mathrm{kg}$ of FVIII concentrate. Compared to patients with on-demand therapy, children on prophylaxis had fewer bleeds in general (0.52 vs 1.08 bleeds/patient/month; $P<0.05)$ and fewer hemarthroses $(0.2$ vs $0.52 ; P<0.02)$. Radiographic evaluation disclosed hemophilic arthropathy in $29 \%$ of patients on prophylaxis compared to $74 \%$ of on-demand patients $(P<0.05)$. Factor inhibitors developed in three prophylaxis and two on-demand patients.

Results of the Joint Outcome Study (JOS) conducted in the United States were published in $2007 .{ }^{65}$ This trial enrolled 65 boys from 1996 to 2000 . Eligibility criteria included age less than 30 months, a FVIII level of $2 \%$ or less, normal baseline radiographic studies, and no more than two prior hemorrhages in any index joint (knee, ankle, and elbow). None of the participants had a history of an inhibitor. Thirty-three patients on the on-demand treatment arm received $40 \mathrm{IU} / \mathrm{kg}$ at the onset of joint bleeding, $20 \mathrm{IU} / \mathrm{kg}$ each 24 and 72 hours after the initial infusion and then every other day until resolution of joint pain and impaired immobility. Thirty-two patients received prophylaxis with $25 \mathrm{IU} / \mathrm{kg}$ every other day. The primary outcome measurement was the number of patients in each cohort with radiographic (MRI and plain-film) evidence 
of bone or cartilage damage in the index joints at the age of 6 years. Ninety-three percent of the boys in the prophylaxis group as opposed to $55 \%$ of individuals in the episodic treatment group had normal index-joints.

High-titer factor inhibitors developed in two patients receiving prophylactic infusions. Three patients on episodic therapy sustained life threatening hemorrhages.

Interestingly, the number of clinically evident joint bleeding episodes correlated only weakly with the outcome as measured by MRI studies. The investigators concluded that the absence of overt hemarthroses and joint abnormalities on physical examination may lead to the erroneous assumption that on-demand factor infusions in younger boys are effective. They postulated that repeat microhemorrhages may cause damage without obvious evidence of heamarthroses.

While the results of alternate day prophylaxis were clearly superior to enhanced episodic factor therapy, the investigators were cognizant of the high cost of this preventative approach. Factor consumption in the prophylaxis group was almost 2.5-fold higher than in the on-demand group (6000 vs 2500 units per year).

\section{Inhibitor development}

After the arrival of recombinant technology-derived factor products with minimal risk of transmission of infectious pathogens, the development of inhibitors is now the most serious treatment-related complication of hemophilia therapy.

Inhibitors render normal therapy ineffective and hemorrhage more difficult to control. They lead to increased morbidity and mortality and higher cost.

Patient-related determinants of inhibitor development include ethnicity, family history and, most importantly, the individuals' FVIII gene mutation. ${ }^{3}$ Several severe genetic defects (large deletions, nonsense mutations, FVIII intron 22 inversions) result in absence of clotting factor. In these patients, exogenous factor therapy represents exposure to a foreign antigen and may elicit a high-titer, FVIII neutralizing immune response.

Approximately $30 \%$ of patients with severe hemophilia A develop a factor inhibitor ${ }^{17,19}$ although in individual series, the rate was as low as $2.7 \%{ }^{66}$ and as high as $52 \%{ }^{67}$ Most inhibitors occur in early childhood with the highest risk within the first twenty exposure days. ${ }^{17,18,68-70}$

Earlier cohort studies suggested an inverse relationship between the age at first exposure and the probability of inhibitor development. ${ }^{71,72}$ Later studies with multivariate analyses adjusted for other variables including family history of inhibitor development as well as FVIII gene mutation did not confirm these results. ${ }^{73,74}$ To the contrary, children starting prophylaxis before the age of three years experienced a $70 \%$ reduction in the risk of inhibitor development. ${ }^{73}$

The CANAL study confirmed the protective effects of prophylaxis. ${ }^{74}$ Three hundred and sixty-six consecutive patients born between 1990 and 2000 were enrolled in this multicenter retrospective cohort study designed to assess the relationship between type of therapy and inhibitor development. A clinically relevant inhibitor was defined as the occurrence of at least 2 positive inhibitor titers combined with a decreased factor recovery. Eighty-seven (24\%) patients developed inhibitors, 69 of whom suffered from a high titer antibody. The incidence of inhibitors initially appeared to be associated with the age at first treatment. Forty-one percent of those treated within the first month of life developed an inhibitor compared to only $18 \%$ in those treated after 18 months. After adjustment for treatment intensity, this association largely disappeared. Surgical procedures and intensive treatment at first FVIII exposure substantially increased the inhibitor risk. In contrast, regular prophylaxis was associated with a $60 \%$ lower risk than ondemand treatment.

The fear that patients would experience an increased probability of developing an inhibitor after switching from a $\mathrm{p} / \mathrm{d}$ factor to a recombinant product has not been substantiated. ${ }^{75}$ The Canadian surveillance study followed 479 previously treated patients for 1 year past conversion to a recombinant factor, and 339 for 2 years. ${ }^{76}$ No increase of new inhibitors was seen, suggesting that recombinant products do not present epitopes different from those on $\mathrm{p} / \mathrm{d}$ products.

The recognition of the protective effects of early low-dose prophylaxis has led many centers to pursue an incremental FVIII dosing approach in which patients initially receive once a week prophylaxis unless bleeding develops. ${ }^{77}$ Over a several months period, the infusion frequency is then increased to twice or three times a week therapy.

\section{Consideration of cost in hemophilia prophylaxis}

Although no consensus exists on the exact dosing schedule of prophylaxis, regular administration of recombinant FVIII in the pediatric age group is now accepted as the most effective treatment to prevent hemarthrosis, hospitalization, and arthropathy. Recent recommendations from the National Hemophilia Foundation extend the concept of prophylaxis as standard of care for severe hemophilia to patients of all ages. Epidemiologic data show improved care and long-term well-being in patients in general. 
The high cost of rFVIII concentrate has been considered a major obstacle in the widespread acceptance of prophylaxis. In most countries of the developing world, such therapy is impractical, and even the reduced expense of $\mathrm{p} / \mathrm{d}$ factor concentrates may be prohibitive. The presumed beneficial financial impact of markedly decreased hospitalization rates $^{48}$ and a $60 \%$ to $70 \%$ lower risk of inhibitor development compared to on-demand therapy ${ }^{73,74}$ has not been quantified in these studies.

As the recent Joint Outcome study has shown, ${ }^{65}$ factor consumption of patients on routine prophylaxis exceeds that of episodic treatment 2.5 -fold. The estimated annual cost of prophylaxis for a patient weighing $50 \mathrm{~kg}$ was thought to amount to US\$300,000.

A cost-effectiveness study was recently published by investigators from Canada. ${ }^{78}$ Three distinct treatment regimens were investigated for their impact on incremental cost per joint-hemorrhage avoided, and on quality-adjustedlife-year (QALY) gained. The treatments included standard prophylaxis, tailored (escalated) dose prophylaxis, and on-demand therapy. Costs considered in this analysis included factor concentrates, professional visits and tests, placement of central venous access and complications encountered, hospitalizations, home health care expenditures, and parents' or caregivers' work days lost. The costs of escalated-dose prophylaxis amounted to an additional US $\$ 3,000$ per joint hemorrhage avoided compared to on-demand therapy, and US $\$ 9,000$ for standard prophylaxis compared to on-demand therapy. The incremental cost per QALY for escalated dose vs on-demand therapy was US\$542,000. Prophylaxis was thought to improve clinical outcome and quality of life compared to on-demand treatment but at a substantial increase in cost.

The increased life expectancy of patients now receiving safe factor concentrates without the risk of viral transmission will translate into health considerations not heretofore encountered. In essence, a disorder previously restricted by and large to the pediatric and young adult age group is now evolving into a disease of older adulthood with consequences reaching into geriatrics. Improperly treated hemophilia patients will pose great demands on national health care systems.

Expenditures related to an increased median annual factor consumption of patients on prophylaxis (3024 IU $/ \mathrm{kg}$ vs $780 \mathrm{IU} / \mathrm{kg}$ for on-demand treatment) may be offset by the reduced costs of fewer surgeries such as arthrodeses, implantation of prostheses, and synovectomies. ${ }^{79}$ These considerations do not take into account the additional positive economic effects of regular school attendance and uninterrupted work activities.

Children with severe hemophilia may have reduced bone mineral density (BMD) compared with age-matched controls, ${ }^{27}$ but prophylaxis starting in early childhood may preserve normal BMD and reduce the risk of degenerative bone disease, pathologic fractures, and the financial burden that such problems impose. ${ }^{80}$

The Economics Expert Working Group for the International Prophylaxis Study Group has developed recommendations for minimal core standards to be applied to the reporting of economic evaluations of hemophilia prophylaxis. These standards will facilitate the comparison of studies and allow rational policy decisions and treatment choices in the future. ${ }^{81}$

\section{Conclusions}

Nonrandomized as well as randomized studies have accumulated a plethora of data on prophylactic FVIII infusions in patients with severe hemophilia A, documenting the beneficial results of decreased bleeding episodes and later degenerative joint disease. Nevertheless, a number of barriers exist to implementation of such therapy as divergent practice patterns in the western world substantiate. Such barriers include inadequate intravenous access especially in young children, lack of understanding on the part of caregivers, fear of the development of an inhibitor, psychological factors, and not least the exorbitant cost of recombinant factor therapy.

Key questions as yet unanswered include the optimal age at onset of prophylaxis, the optimal dosage and schedule of infusions, and the proper clinical and laboratory follow up. Needed are prospective studies with different prophylactic regimens and objective outcome measures that take into consideration issues such as inhibitor development and cost of therapy.

As several recent prophylaxis studies with larger patient population have shown, bleeding episodes can be dramatically curtailed ${ }^{82-85}$ only as long as patient compliance with the regimen is maintained. ${ }^{84,85}$ Lack of adherence to the intended regimen was the most important determinant of low FVIII levels and increased bleeding, although in children aged 1-6, the rate of hemorrhage was also influenced by the FVIII half-life and clearance..$^{85}$

New factor preparations with extended half-life are in clinical studies. If proven effective, such factor concentrates will significantly decrease the frequency of factor infusions, thus likely increasing compliance. Gene therapy, now under 
investigation, constitutes a possible alternative to prophylaxis, with curative potential.

\section{Disclosure}

The author declares no conflicts of interest.

\section{References}

1. Rosner F. Hemophilia in classic Rabbinic texts. J Hist Med Allied Sci. 1994;49:240-250.

2. Patek AJ. Hemophilia II: Some properties of a substance obtained from normal plasma effective in accelerating the clotting of hemophilic blood. J Clin Invest. 1937;16:113-124.

3. Goodeve AC, Peake IR. The molecular basis of hemophilia A: genotypephenotype relationships and inhibitor development. Semin Thromb Hemost. 2003;29:23-30.

4. Ikkala E, Heilske T, Myllyla G, et al. Changes in the life expectancy of patients with severe haemophilia A in Finland in 1930-1979. Br J Haematol. 1982;52:7-12.

5. Chorba TL, Holman RC, Strine TW, et al. Changes in longevity and causes of death among persons with hemophilia A. Am J Hematol. 1994;45:112-121.

6. Meija-Carvajal C, Czapek EE, Valentino LA. Life expectancy in hemophilia outcome. J Thromb Haemost. 2006;4:507-509.

7. Donadel-Claeyssens S. Current coordinated activities of the PEDNET (European Paediatric Network for Haemophilia Management). Haemophilia. 2006;12:124-127.

8. Pool JG, Hershgold EJ, Pappenhagen AR. High-potency antihaemophilic factor concentrate prepared from cryoglobulin precipitate. Nature. 1964;203:312.

9. Rotblat F, Goodall AH, O'BRien DP, et al. Monoclonal antibodies to human procoagulant factor VIII. J Lab Clin Med. 1983;101:736-746.

10. Gitschier J, Wood WI, Goralka TM, et al. Characterization of the human factor VIII gene. Nature. 1984;312:326-330.

11. Toole JJ, Knopf JL, Wozney JM, et al. Molecular cloning of a cDNA encoding human antihemophilic factor. Nature. 1984; 312:342-347.

12. White GC, McMillan CW, Kingdon HS, et al. Use of recombinant antihemophilic factor in the treatment of two patients with classic hemophilia. N Engl J Med. 1989;323:166-170.

13. Schwartz RS, Abilgaard CF, Aledort LM, et al. Human recombinant DNA-derived antihemophilic factor (factor VIII) in the treatment of hemophilia. N Engl J Med. 1990;323:1800-1805.

14. Mitterer A, Kaliwoda M, Kumar HPM, et al. Recombinant FVIII manufactured without the use of animal/human derived substances (rAHF-PFM). [Abstract]. Blood. 2002;100:92b.

15. Abshire TC, Brackmann HH, Scharrer I, et al. Sucrose formulated recombinant antihemophilia factor FVIII is safe and efficacious for treatment of hemophilia A in home therapy. Thromb Haemost. 2000;83:811-816.

16. Tarantino MD, Navale LM, Bray GL, et al. Clinical evaluation of a new generation recombinant FVIII, plasma/albumin-free method (rAHFPFM). [Abstract]. Blood. 2002;100:493a.

17. Lusher JM, Arkin S, Abildgaard CF, et al. Recombinant factor VIII for the treatment of previously untreated patients with hemophilia A. N Engl J Med. 1993;328:453-459.

18. Lusher JM. Recombinant clotting factors. A review of current clinical status. Bio-Drugs. 2000;13:289-298.

19. Bray GL, Gomperts ED, Courter S. A multicenter study of recombinant factor VIII (Recombinate): safety, efficacy, and inhibitor risk in previously untreated patients with hemophilia A. Blood. 1994; 83:2428-2435.

20. White GC, Courter S, Bray GL, et al. A multicenter study of recombinant factor VIII (Recombinate) in previously treated patients with hemophilia A. Thromb Haemost. 1997;77:660-667.
21. Lusher JM, Lee CA, Kessler CM, et al. The safety and efficacy of B domain deleted recombinant factor VIII concentrate in patients with severe hemophilia A. Haemophilia. 2003;9:38-49.

22. Ahnstrom J, Berntorp E, Lindvall K, et al. A 6-year follow-up of dosing, coagulation factor levels and bleedings in relation to joint status in the prophylactic treatment of haemophilia. Haemophilia. 2004;10:689-697.

23. Valentino LA, Hakobyan N, Kazarian T, et al. Experimental haemophilic synovitis: rationale and development of a murine model of human factor VIII deficiency. Haemophilia. 2004;10:280-287.

24. Roosendaal G, Lafeber FP. Blood-induced joint damage in hemophilia. Semin Thromb Hemost. 2003;29:37-42.

25. Wen FQ, Jabbar AA, Chen YX, et al. C-myc proto-oncogene expression in hemophilic synovitis: in vitro studies of the effects of iron and ceramide. Blood. 2002;100:912-916.

26. Pettersson H, Ahlberg A, Nilsson IM. A radiologic classification of hemophilia arthropathy. Clin Orthop. 1980;149:153-159.

27. Abdelrazik N, Reda M, El-Ziny M, et al. Evaluation of bone mineral density in children with hemophilia: Mansoura University children hospital (MUCH) experience, Mansoura, Egypt. Hematology. 2007; $12: 431-437$.

28. Aledort LM, Haschmeyer RH, Pettersson H. A longitudinal study of orthopaedic outcomes for severe factor-VIII-deficient haemophiliacs. The Orthopaedic Outcome Study Group. J Intern Med. 1994; 236:391-399.

29. Fisher K, van der Bo JG, Mauser-Bunschoten EP, et al. The effects of postponing prophylactic treatment on long-term outcome in patients with severe hemophilia. Blood. 2002;99:2337-2341.

30. Fisher K, van Hout BA, van der Bom JG, et al. Association between joint bleeds and Pettersson scores in severe haemophilia. Acta Radiol. 2002;43:528-532.

31. Nilsson IM, Blomback M, Ahlberg A. Our experience in Sweden with prophylaxis on haemophilia. Bibl Haematol. 1970;34:111-124.

32. Van Creveld S. Prophylaxis of joint hemorrhages in hemophilia. Acta Haematol. 1969;41:206-214.

33. Kasper CK, Dietrich SL, Rapaport SI. Hemophilia prophylaxis with factor VIII concentrate. Arch Intern Med. 1970;125:1004-1009.

34. Manco-Johnson MJ, Nuss R, Geraghty S, et al. Results of secondary prophylaxis in children with severe hemophilia. Am J Hematol. 1994;47:113-117.

35. Kreuz W, Escuriola-Ettingshausen C, Funk M, et al. When should prophylactic treatment in patients with haemophilia A and B start? The German experience. Haemophilia. 1998;4:413-417.

36. Nilsson IM, Berntorp E, Lofqvist T, et al. Twenty-five years' experience of prophylactic treatment in severe haemophilia A and B. J Intern Med. 1992;232:25-32.

37. Lofquist T, Nilsson IM, Berntorp E, et al. Haemophilia prophylaxis in young patients-a long-term follow-up. J Intern Med. 1997; 241:395-400.

38. Astermark J, Petrini P, Tengborn L, et al. Primary prophylaxis in severe haemophilia should be started at an early age but can be individualized. Br J Haematol. 1999;105:1109-1113.

39. Carlsson M, Berntorp E, Bjorkman S, et al. Pharmacokinetic dosing in prophylactic treatment of hemophilia A. Eur J Haematol. 1993; 51:247-252.

40. Fisher K, Astermark J, van der Bom JG, et al. Prophylactic treatment for severe hemophilia: comparison of an intermediate-dose to high-dose regimen. Haemophilia. 2002;8:753-760.

41. Blanchette V, Rivard G, Israels S, et al. Musculoskeletal results from the Canadian Hemophilia Dose-Escalation Prophylaxis Trial. [Abstract]. Blood. 2003;102:52a.

42. Feldman BM, Pai M, Rivard GE, et al. Tailored prophylaxis in severe hemophilia: interim results from the first 5 years of the Canadian Hemophilia Primary Prophylaxis Study. J Thromb Haemost. 2006; 4:1228-1236.

43. Berntorp E, Boulyjenkov V, Brettler D. Modern treatment of haemophilia. Bull World Health Organ. 1995;73:691-701. 
44. Medical and Scientific Advisory Council. MASAC Recommendation Concerning Prophylaxis (Regular Administration of Clotting Factor Concentrate to Prevent Bleeding). New York, NY: National Hemophilia Foundation; 2006. MASAC Recommendation 170.

45. Srivastava A, Giangrande P, Poon MC, et al. Guidelines for the Management of Hemophilia. Available at: http://www/wfh.org/2/docs/ Publications/Diagnosis_and_Treatment/Guidelines_Mng_Hemophilia. pdf. Montreal, Quebec: World Federation of Hemophilia; 2005.

46. Schobess R, Kurnik K, Friedrichs F, et al. Effects of primary and secondary prophylaxis on the clinical expression of joint damage in children with severe haemophilia A. Thromb Haemost. 2008; 99:71-76.

47. den Uijl IEM, Fischer K. Including the life-time cumulative number of joint bleeds in the definition of primary prophylaxis. [letter]. Thromb Haemost. 2008;99:965.

48. Plug I, van der Bom JG, Peters M, et al. Thirty years of hemophilia treatment in the Netherlands, 1972-2001. Blood. 2004;104:3494-3500.

49. Khair K, Lawrence K, Butler R, et al. Assessment of treatment practice patterns for severe hemophilia A: a global nurse perspective. Acta Haematol. 2008;119:115-123.

50. Biss TT, Chan AK, Blanchette VS, et al. The use of prophylaxis in 2663 children and adults with haemophilia: results of the 2006 Canadian national haemophilia prophylaxis survey. Haemophilia. 2008; 14:923-930.

51. Taki M, Shirata A. Current situation of regular replacement therapy (prophylaxis) for haemophilia in Japan. Haemophilia. 2009;15: $78-82$.

52. Butler RB, McClure W, Wulff K. Practice patterns in haemophilia A therapy-a survey of treatment centers in the United States. Haemophilia. 2003;9:549-554.

53. Geraghty S, Dunkley T, Harrington C, et al. Practice patterns in haemophilia A therapy-global progress towards optimal care. Haemophilia. 2006;12:75-81.

54. Blanchette VS, McCready M, Achonu C, et al. A survey of factor prophylaxis in boys with haemophilia followed in North American haemophilia treatment centers. Haemophilia. 2003; 9 Suppl:19-26.

55. Van Dijk K, Fisher K, van der Bom JG, et al. Can long-term prophylaxis for severe haemophilia be stopped in adulthood? Results from Denmark and the Netherlands. Br J Haematol. 2005;130: $107-112$

56. Richards M, Altisent C, Batorova A, et al. Should prophylaxis be used in adolescent and adult patients with severe haemophilia? A European survey of practice and outcome data. Haemophilia. 2007; 13:473-479.

57. Tagliaferri A, Franchini M, Coppola A, et al. Effects of secondary prophylaxis started in adolescent and adult haemophiliacs. Haemophilia. 2008; 14:945-951.

58. Fisher K, Valentino L, Ljung R. Prophylaxis for severe haemophilia: clinical challenges in the absence as well as in the presence of inhibitors. Haemophilia. 2008;14 Suppl 3:196-201.

59. Walsh CE; Adult Prophylaxis Study Group. Prophylaxis for adults with severe haemophilia: a compelling need for evidence-based guidelines [letter]. Haemophilia. 2008;14:385-386.

60. Aronstam A, Arblaster PG, Rainsford SG, et al. Prophylaxis in haemophilia: a double-blind controlled trial. Br J Haematol. 1976; 33:81-90.

61. Aronstam A, Kirk PJ, McHardy J, et al. Twice weekly prophylactic therapy in haemophilia A. J Clin Pathol. 1977;30:65-67.

62. Carlsson M, Berntorp E, Bjorkman S, et al. Improved cost-effectiveness by pharmacokinetic dosing of factor VIII in prophylactic treatment of haemophilia A. Haemophilia. 1997;3:96-101.

63. Morfini M, Mannucci PM, Mariani G, et al. Evaluation of prophylactic replacement therapy in haemophilia B. Scand J Haematol. 1976;16:41-47.

64. Gringery A. A 10-year, randomized, clinical trial on prophylaxis vs on-demand treatment in children with haemophilia A: the E.S.P.R.I.T. study. [Abstract]. Haemophilia. 2008;14 Suppl 2:99.
65. Manco-Johnson M, Abshire T, Shapiro A, et al. Prophylaxis versus episodic treatment to prevent joint disease in boys with severe hemophilia. N Engl J Med. 2007;357:535-544.

66. Yee TT, Williams MD, Hill FG, et al. Absence of inhibitors in previously untreated patients with severe haemophilia A after exposure to a single intermediate purity factor VIII product. Thromb Haemost. 1997;78:1027-1029.

67. Ehrenforth S, Kreuz W, Scharrer I, et al. Incidence of development of factor VIII and factor IX inhibitors in haemophiliacs. Lancet. 1992;339:594-598.

68. Giangrande PLF; for the Kogenate Bayer Study Group. Safety and efficacy of Kogenate Bayer in previously untreated patients (PUPs) and minimally treated patients (MTPs). Haemophilia. 2002; 8 Suppl 2:19-22.

69. Wight J, Paisley S. The epidemiology of inhibitors in haemophilia A: a systemic review. Haemophilia. 2003;9:418-435.

70. Lusher J, Abilgaard C, Arkin S, et al. Human recombinant DNA-derived antihemophilic factor in the treatment of previously untreated patients with hemophilia A: final report on a hallmark clinical investigation. J Thromb Haemost. 2004;24:574-583.

71. van der Bom JG, Mauser-Bunschoten EP, Fischer K, et al. Age at first treatment and immune tolerance to factor VIII in severe hemophilia. Thromb Haemost. 2003;89:475-479.

72. Lorenzo JI, Lopez A, Altisent C, et al. Incidence of factor VIII inhibitors in severe hemophilia: the importance of patient age. Br J Haematol. 2001;113:600-603.

73. Santagostino E, Mancuso ME, Rocino A, et al. Environmental risk factors for inhibitor development in children with haemophilia A a case-control study. Br J Haematol. 2005;130:422-427.

74. Gouw SC, van der Bom JG, Marijke van den Berg H. Treatmentrelated risk factors of inhibitor development in previously untreated patients with hemophilia A: the CANAL cohort study. Blood. 2007; 109:4648-4654.

75. Scharrer I, Ehrlich HJ. Lack of evidence for increased inhibitor incidence in patients switched from plasma-derived to recombinant factor VIII. Haemophilia. 2001;7:346-348.

76. Giles AR, Rivard GE, Teitel J, et al. Surveillance for factor VIII inhibitor development in the Canadian hemophilia A population following the widespread introduction of recombinant factor VIII replacement therapy. Transfus Sci. 1998;19:139-148.

77. Mancuso ME, Graca L, Auerswald G, et al. Haemophilia care in children - benefits of early prophylaxis for inhibitor prevention. Haemophilia. 2009;15 Suppl 1:8-14.

78. Risebrough N, Oh P, Blanchette V, et al. Cost-utility analysis of Canadian tailored prophylaxis, primary prophylaxis and on demand therapy in young children with severe haemophilia A. Haemophilia. 2008; $14: 743-752$.

79. Steen Carlsson K, Hojgard S, Glomstein A, et al. On-demand vs prophylactic treatment for severe haemophilia in Norway and Sweden: differences in treatment characteristics and outcome. Haemophilia. 2003;9:555-566.

80. Khawaji M, Akesson K, Berntorp E. Long-term prophylaxis in severe haemophilia seems to preserve bone mineral density. Haemophilia. 2009;15:261-266.

81. Nicholson A, Berger K, Bohn R, et al. Recommendations for reporting economic evaluations of haemophilia prophylaxis: a nominal group's consensus statement on behalf of the Economics Expert Working Group for The International Prophylaxis Study Group. Haemophilia. 2008;14:127-132.

82. Blanchette VS, Shapiro AD, Liesner RJ, et al. Plasma and albuminfree recombinant factor VIII: pharmacokinetics, efficacy and safety in previously treated pediatric patients. J Thromb Haemost. 2008; 6:1319-1326.

83. Pollmann H, Externest D, Ganser A, et al. Efficacy, safety, and tolerability of recombinant factor VIII (REFACT) in patients with hemophilia A: interim data from a post marketing surveillance study in Germany and Austria. Haemophilia. 2007;13:131-143. 
84. Shapiro A, Gruppo R, Pabinger I, et al. Integrated analysis of safety and efficacy of a plasma- and albumin-free recombinant factor VIII (rAHF-PFM) from six clinical studies in patients with hemophilia A. Expert Opin Biol Ther. 2009;9:273-283.
85. Collins PW, Blanchette VS, Fischer K, et al. Break-through bleeding in relation to predicted factor VIII levels in patients receiving prophylactic treatment for severe hemophilia A. J Thromb Haemost. 2009;7: 413-420.

\section{Publish your work in this journal}

Vascular Health and Risk Management is an international, peerreviewed journal of therapeutics and risk management, focusing on concise rapid reporting of clinical studies on the processes involved in the maintenance of vascular health; the monitoring, prevention and treatment of vascular disease and its sequelae; and the involvement of metabolic disorders, particularly diabetes. This journal is indexed on PubMed Central and MedLine. The manuscript management system is completely online and includes a very quick and fair peer-review system, which is all easy to use. Visit http://www.dovepress.com/ testimonials.php to read real quotes from published authors.

Submit your manuscript here: http://www.dovepress.com/vascular-health-and-risk-management-journal 